\title{
Crystal structure of pyrene-4-aldehyde, $\mathrm{C}_{17} \mathrm{H}_{10} \mathrm{O}$
}

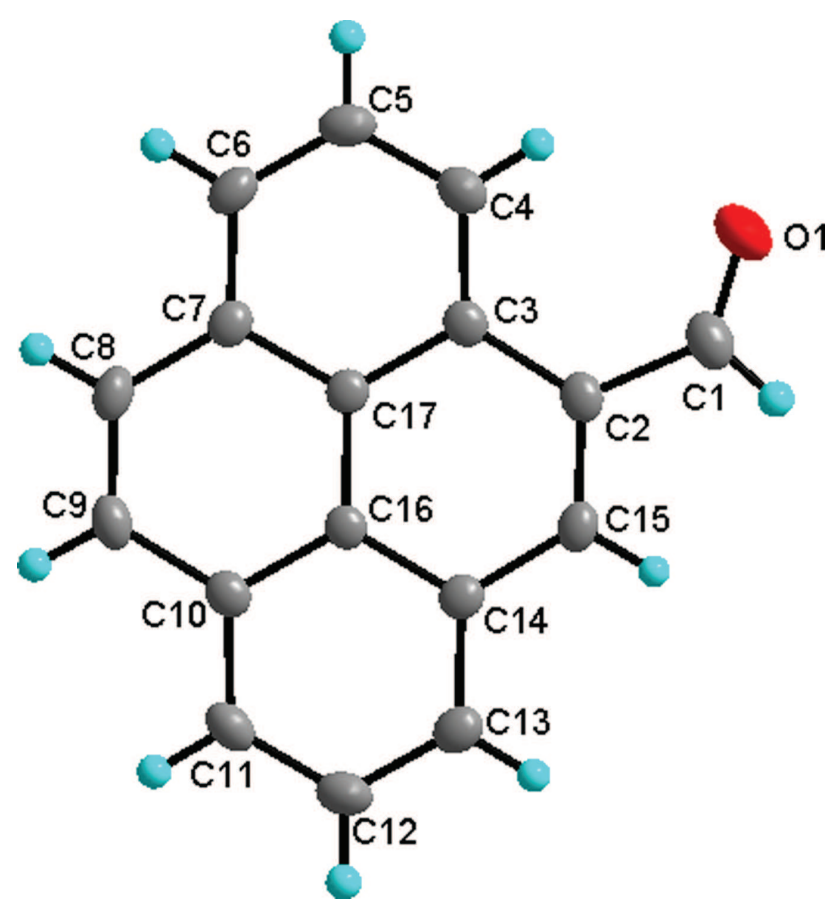

https://doi.org/10.1515/ncrs-2018-0254

Received July 20, 2018; accepted September 8, 2018; available online September 27, 2018

\section{Abstract \\ $\mathrm{C}_{17} \mathrm{H}_{10} \mathrm{O}$, monoclinic, $P 2_{1} / c \quad$ (no. 14), $a=9.3121(19) \AA$, $b=8.0958(16) \AA, \quad c=14.944(3) \AA, \quad \beta=106.06(3)^{\circ}, \quad V=$ $1082.7(4) \AA^{3}, \quad Z=4, \quad R_{\mathrm{gt}}(F)=0.0488, \quad w R_{\text {ref }}\left(F^{2}\right)=0.1418$, $T=293(2) \mathrm{K}$.}

\section{CCDC no.: 1866559}

The crystal structure is shown in the figure. Tables 1 and 2 contain details on crystal structure and measurement conditions and a list of the atoms including atomic coordinates and displacement parameters.

*Corresponding author: Zhao Yun, School of Chemical Engineering and Technology, China University of Mining and Technology, Xuzhou 221116, Jiangsu Province, P.R. China, e-mail: zhanglifang@cumt.edu.cn

Miao Bao-Xi and Zhang Li-Fang: School of Chemical Engineering and Technology, China University of Mining and Technology, Xuzhou 221116, Jiangsu Province, P.R. China
Table 1: Data collection and handling.

\begin{tabular}{ll}
\hline Crystal: & Yellow block \\
Size: & $0.18 \times 0.16 \times 0.12 \mathrm{~mm}$ \\
Wavelength: & Mo $K \alpha$ radiation $(0.71073 \AA)$ \\
$\mu:$ & $0.09 \mathrm{~mm}^{-1}$ \\
Diffractometer, scan mode: & Bruker APEX II, $\varphi$ and $\omega$ \\
$\theta_{\max }$, completeness: & $27.5^{\circ}, 99 \%$ \\
$N(h k l)_{\text {measured }}, N(h k l)_{\text {unique }}, R_{\text {int }}:$ & $8542,2430,0.025$ \\
Criterion for $I_{\text {obs }}, N\left(h k l_{\text {gt }}:\right.$ & $I_{\text {obs }}>2 \sigma\left(I_{\text {obs }}\right), 1957$ \\
$N(\text { param })_{\text {refined }}:$ & 163 \\
Programs: & SHELX [1], PLATON [2] \\
\hline
\end{tabular}

Table 2: Fractional atomic coordinates and isotropic or equivalent isotropic displacement parameters $\left(\AA^{2}\right)$.

\begin{tabular}{lrrrr}
\hline Atom & $\boldsymbol{x}$ & $\boldsymbol{y}$ & $\boldsymbol{z}$ & $\boldsymbol{U}_{\text {iso }}{ }^{*} \boldsymbol{U}_{\text {eq }}$ \\
\hline O1 & $0.08571(11)$ & $0.73278(15)$ & $-0.11159(8)$ & $0.0413(3)$ \\
C1 & $0.21356(16)$ & $0.70645(18)$ & $-0.10688(11)$ & $0.0312(3)$ \\
H1 & 0.2292 & 0.6473 & -0.1567 & $0.037^{*}$ \\
C2 & $0.35103(15)$ & $0.75278(16)$ & $-0.03459(9)$ & $0.0225(3)$ \\
C3 & $0.35280(14)$ & $0.85347(15)$ & $0.04612(9)$ & $0.0207(3)$ \\
C4 & $0.22445(15)$ & $0.92042(17)$ & $0.06338(10)$ & $0.0257(3)$ \\
H4 & 0.1313 & 0.8990 & 0.0223 & $0.031^{*}$ \\
C5 & $0.23448(16)$ & $1.01847(17)$ & $0.14111(10)$ & $0.0287(3)$ \\
H5 & 0.1479 & 1.0619 & 0.1513 & $0.034^{*}$ \\
C6 & $0.37110(16)$ & $1.05240(17)$ & $0.20352(10)$ & $0.0267(3)$ \\
H6 & 0.3753 & 1.1184 & 0.2551 & $0.032^{*}$ \\
C7 & $0.50348(15)$ & $0.98879(16)$ & $0.19010(9)$ & $0.0222(3)$ \\
C8 & $0.64717(16)$ & $1.02360(17)$ & $0.25327(9)$ & $0.0265(3)$ \\
H8 & 0.6531 & 1.0916 & 0.3043 & $0.032^{*}$ \\
C9 & $0.77384(16)$ & $0.95971(18)$ & $0.24020(9)$ & $0.0268(3)$ \\
H9 & 0.8651 & 0.9828 & 0.2829 & $0.032^{*}$ \\
C10 & $0.76971(14)$ & $0.85646(16)$ & $0.16119(9)$ & $0.0227(3)$ \\
C11 & $0.89839(15)$ & $0.78834(18)$ & $0.14545(10)$ & $0.0274(3)$ \\
H11 & 0.9906 & 0.8074 & 0.1882 & $0.033^{*}$ \\
C12 & $0.89127(15)$ & $0.69253(18)$ & $0.06709(10)$ & $0.0289(3)$ \\
H12 & 0.9784 & 0.6488 & 0.0579 & $0.035^{*}$ \\
C13 & $0.75612(15)$ & $0.66206(17)$ & $0.00307(10)$ & $0.0262(3)$ \\
H13 & 0.7529 & 0.5989 & -0.0494 & $0.031^{*}$ \\
C14 & $0.62341(15)$ & $0.72504(16)$ & $0.01608(9)$ & $0.0209(3)$ \\
C15 & $0.48051(15)$ & $0.69448(16)$ & $-0.04799(9)$ & $0.0232(3)$ \\
H15 & 0.4759 & 0.6322 & -0.1010 & $0.028^{*}$ \\
C16 & $0.62911(14)$ & $0.82350(15)$ & $0.09584(9)$ & $0.0191(3)$ \\
C17 & $0.49502(14)$ & $0.88801(15)$ & $0.11076(8)$ & $0.0194(3)$ \\
\hline & & & &
\end{tabular}

\section{Source of material}

All chemicals were purchased from commercial sources and used as received. The title compound was prepared 
by two steps. The intermediate 4-cyanopyrene was prepared by the following procedures. To a $100 \mathrm{~mL}$ two-necked flask, 4-bromopyrene (0.327 g, $1.164 \mathrm{mmol})$, CuCN (0.215 g, $2.4 \mathrm{mmol}$ ), and anhydrous DMF (30 mL) were added. The mixture was heated at $160{ }^{\circ} \mathrm{C}$ for 3 days, and then cooled down to $90{ }^{\circ} \mathrm{C}$. Subsequently, a mixture of ethylenediamine $(10 \mathrm{~mL})$ and water $(15 \mathrm{~mL})$ was added. The resulting mixture was stirred at $90{ }^{\circ} \mathrm{C}$ for $3 \mathrm{~h}$ and then cooled to room temperature. The product was extracted with dichloromethane three times and the organic layer was dried over magnesium sulfate, filtered, and evaporated. A quantity of $0.2 \mathrm{~g}$ (76\% yield) of $\mathrm{C}_{17} \mathrm{H}_{9} \mathrm{~N}$ was isolated as pale green crystals. IR (KBr): $3043 \mathrm{~cm}^{-1}, 2220 \mathrm{~cm}^{-1} .{ }^{1} \mathrm{H} \mathrm{NMR}\left(400 \mathrm{MHz}, \mathrm{CDCl}_{3}\right) \delta$ $8.66-8.55$ (m, 2H), $8.41-8.25$ (m, 3H), $8.22-8.06$ (m, 4H). GC/MS MS: $\left(\mathrm{C}_{17} \mathrm{H}_{9} \mathrm{~N}\right) \mathrm{m} / \mathrm{z} 227\left(\mathrm{M}^{+}, 100\right), 200(16), 100(20)$.

The title compound was synthesized by dehydrogenation of the above intermediate4-cyanopyrene: an oven-dried $50 \mathrm{~mL}$ flask which was equipped with a side arm, a condenser, and adapter was flushed with nitrogen and charged with $0.150 \mathrm{~g}$ ( $0.66 \mathrm{mmol})$ of 4-cyanopyrene and $30 \mathrm{~mL}$ of $\mathrm{CH}_{2} \mathrm{Cl}_{2}$. The solution was cooled to $0{ }^{\circ} \mathrm{C}$ in an ice-water bath and $0.8 \mathrm{~mL}$ of $1 \mathrm{M}$ solution of DIBAL-H in $\mathrm{n}$-hexane was added slowly with stirring. After $15 \mathrm{~min}$, additional $0.8 \mathrm{~mL}$ of $1 \mathrm{M}$ solution of DIBAL-H in $\mathrm{n}$-hexane was added slowly. The mixture was stirred for $3 \mathrm{~h}$ at room temperature. The mixture was poured into $50 \%$ sulfuric acid water solution and extracted with $\mathrm{CH}_{2} \mathrm{Cl}_{2}$ two times. The organic layer was washed with water, dried over $\mathrm{MgSO}_{4}$ and concentrated in vacuo. The residue was purified by silica gel chromatography using hexane $/ \mathrm{CH}_{2} \mathrm{Cl}_{2}$ as an eluent to afford $0.1 \mathrm{~g}$ pyrene-4aldehyde in $66 \%$ yield. IR (KBr): $2724 \mathrm{~cm}^{-1}, 1686 \mathrm{~cm}^{-1} \cdot{ }^{1} \mathrm{H}$ NMR (400 MHz, $\left.\mathrm{CDCl}_{3}\right) \delta 10.55(\mathrm{~d}, \mathrm{~J}=0.9 \mathrm{~Hz}, 1 \mathrm{H}), 9.64(\mathrm{~d}$, $\mathrm{J}=8.0 \mathrm{~Hz}, 1 \mathrm{H}), 8.60(\mathrm{~d}, \mathrm{~J}=1.2 \mathrm{~Hz}, 1 \mathrm{H}), 8.35(\mathrm{~d}, \mathrm{~J}=7.7 \mathrm{~Hz}$, $2 \mathrm{H}), 8.29(\mathrm{~d}, \mathrm{~J}=7.6 \mathrm{~Hz}, 1 \mathrm{H}), 8.22-8.02(\mathrm{~m}, 4 \mathrm{H})$. GC/MS MS: $\left(\mathrm{C}_{17} \mathrm{H}_{10} \mathrm{O}\right) \mathrm{m} / \mathrm{z} 230\left(\mathrm{M}^{+}, 60\right), 202(100), 100(25)$. The yellow block crystals of the title compound were obtained by slow evaporation of hexane $/ \mathrm{CH}_{2} \mathrm{Cl}_{2}$ solution $(\mathrm{v}: \mathrm{v}=1 / 1)$.

\section{Experimental details}

All $\mathrm{H}$ atoms bond were introduced using the HFIX commond in the SHELXL program [1]. All $\mathrm{H}$ atoms were allowed for as riding atoms with $U_{\text {iso }}(\mathrm{H})=1.2 U_{\text {eq }}(\mathrm{C})$. The structure was checked using PLATON [2].

\section{Comment}

Since its discovery in 1837 [3], pyrene as one of the most known polyaromatic hydrocarbons (PAHs) has been paid much attention in the development of organic fluorescent materials [4-6]. In the last decades, numerous investigations have been carried out on the design and synthesis of pyrene-based materials with a broad range of potential applications such as organic light-emitting diodes (OLED), organic field effect transistor (OFET), organic lasers, chemosensors and solar cells, etc. [7-11], due to their pure blue fluorescence with high quantum yield, exceptionally long fluorescence lifetime, excellent thermal stability, and high charge carrier mobility. In order to obtain excellent pyrene-based functional materials, much efforts have been made to modify its molecular structure by introducing suitable electrondonating or -accepting groups at different positions of the pyrene. The formyl group is a useful substituent group for interesting pyrene-based functional materials [12]. Generally, a direct formylation on the pyrene ring occurs almost exclusively at the electron rich 1-position of pyrene [13]. Nevertheless, pyrene-2-aldehyde have been successfully designed and synthesized through the formylation and aromatization using 4,5,9,10-tetrahydropyrene as the starting material and its crystal structure has been reported by our group recently [14]. As part of our work on pyrene-based derivatives, we synthesized pyrene-4-aldehyde using a new effective strategy through reduction of 4-cyanopyrene from 4-bromopyrene.

The single X-ray diffraction analysis shows the expected structure of the title compound pyrene-4-aldehyde. The aldehyde group locates at the 4-position of the pyrene. The $\mathrm{C}-\mathrm{O}$ bond length is 1.1923(18) A, similar to that of our previously reported pyrene-2-aldehyde [14]. The $\mathrm{C} 1-\mathrm{C} 2$ bond length is $1.4770(19) \AA$, indicating the $\pi-\pi$ conjugation effect between the pyrene and the aldehyde group. All the carbon and oxygen atoms are nearly in a strict plane with the largest deviation 0.062(2) A. The suprmolecular structure is also comparable with that of its isomer pyrene-2-aldehyde [14]. Firsly, two molecules of the title compound form a dimeric unit by relatively strong $\pi-\pi$ interactions with the shortest interatomic distance of 3.359(2) A. These dimeric structures are linked into a three-dimensional structure by weak $\mathrm{C}-\mathrm{H} \cdots \pi$ and $\mathrm{C}-\mathrm{H} \cdots \mathrm{O}$ interactions.

Acknowledgements: This work was supported by the Fundamental Research Funds for the Central Universities (2017BSCXA05).

\section{References}

1. Sheldrick, G. M.: Crystal structure refinement with SHELXL. Acta Crystallogr. C71 (2015) 3-8.

2. Spek, A. L.: Single-crystal structure validation with the program PLATON. J. Appl. Crystallogr. 36 (2003) 7-13.

3. Laurent, A.: Pyrene from coal tar. Ann. Chim. Phys. 66 (1837) 136-137.

4. Zhang, R.; Sun, H.; Zhao,Y.; Tang, X. X.; Ni, Z. H.: Dipolar 1,3,6,8-tetrasubstituted pyrene-based blue emitters containing electro-transporting benzimidazole moieties: 
syntheses, structures, optical properties, electrochemistry and electroluminescence. Dyes Pigments 152 (2018) 1-13.

5. Figueira-Duarte, T. M.; Mullen, K.: Pyrene-based materials for organic electronics. Chem. Rev. 111 (2011) 7260-7314.

6. Zhang, R.; Zhao, Y.; Zhang, L. F.; Xu, L.; Ni, Z. H.: A series of short axially symmetrically $1,3,6,8$-tetrasubstituted pyrenebased green and blue emitters with 4-tert-butylphenyl and aryamine attachments. Dyes Pigments 130 (2016) 106-115.

7. Zhang, R.; Zhao, Y.; Zhang, L. F.; Xu, L.; Ni, Z. H.: A series of short axially symmetrically $1,3,6,8$-tetrasubstituted pyrene-based green and blue emitters with 4-tert-butylphenyl and aryamine attachments. Dyes Pigments 130 (2016) 106-115.

8. Oniwa, K.; Kikuchi, H.; Shimotani, H.; Ikeda, S.; Asao, N.; Yamamoto, Y.; Tanigaki, K.; Jin, T. N.: 2-Positional pyrene endcapped oligothiophenes for high performance organic field effect transistors. Chem. Commun. 52 (2016) 4800-4803.

9. Yi, J. P.; Zhao, L.; Xu, W. D.; Liu, C. F.; Lai, W. Y.; Huang, W.: Pyrene-capped starburst emitters as gain media for organic lasers: design, synthesis, and stabilized lasing properties. J. Mater. Chem. C 4 (2016) 7546-7553.

10. Chu, K. H.; Zhou, Y.; Fang, Y.; Wang, L. H.; Li, J. Y.; Yao, C.: Rhodamine-pyrene conjugated chemosensors for ratiometric detection of $\mathrm{Hg}^{2+}$ ions: different sensing behavior between a spirolactone and a spirothiolactone. Dyes Pigments 98 (2013) 339-346.

11. Liu, X.; Luo, G. P.; Cai, X. Y.; Wu, H. B.; Su, S. J.; Cao, Y.: Pyrene terminal functionalized perylene diimide as non-fullerene acceptors for bulk heterojunction solar cells. RSC Adv. 5 (2015) 83155-83163.

12. Liu, Y. F.; Jun, E. J.; Kim, G.; Lee, A. R.; Lee, J. H.; Yoon, J.: A bispyrene derivative as a selective fluorescent probe for RNA. Chem. Commun. 50 (2014) 2505-2507.

13. Yamato, T.; Fujimoto, M.; Nagano, Y.: Electrophilic substitution of 7-tert-butyl-1-substituted pyrenes. A new route for the preparation of 1,3-disubstituted pyrenes. Org. Prep. Proceed. Int. 29 (1997) 320-330.

14. Miao, B. X.; Tang, X. X.; Zhang, L. F.: Crystal structure of pyrene-2-carbaldehyde, $\mathrm{C}_{17} \mathrm{H}_{10} \mathrm{O}$. Z. Kristallogr. NCS 233 (2018) 655-657. 